stances, when the alcoholic is also depressed and has suicidal tendencies, it would seem wise to avoid the drug altogether.

I should like to thank HM Coroner for Bedfordshire for permission to publish details of these cases; the scientific officers at the Home Office Forensic Science Laboratory, Aldermaston, Reading, who performed the analyses; and Dr J C Valentine, consultant pathologist, who performed the post-mortem examination in cases 1 and 5 .

${ }^{1}$ Data Sheet Compendium. London, Association of the British Pharmaceutical Industry, 1977

2 Glatt, M, The Alcoholic and the Help He Needs, part II. London, Priory Press, 1972.

3 Jakobsson, S, and Möller, M, in Abstracts of the Sixth International Meeting of Forensic Sciences, Edinburgh, 1972, p 150. London, Association of the British Pharmaceutical Industry, 1972.

${ }^{4}$ Personal communication from chairman of the Local Pharmaceutical Committee, Bedfordshire.

(Accepted 30 fanuary 1978)

Department of Histopathology, Bedford General Hospital, Bedford MK42 9DJ

JOAN M HORDER, MRCPATH, DMJ(PATH), senior registrar

\section{Meningitis due to chloramphenicol-resistant Haemophilus influenzae type b}

Two strains of Haemophilus influenzae resistant to chloramphenicol have been reported from the USA, ${ }^{1}$ and a resistant non-typable strain has been isolated in Holland. ${ }^{2}$ We report here a case of meningitis due to chloramphenicol-resistant Haemophilus influenzae type $b$ that occurred in Oxfordshire in July 1977.

\section{Case report}

A 19-month-old girl presented after two days' illness with drowsiness, irritability, stiff neck, and vomiting. Cerebrospinal fluid (CSF) showed $8.5 \times 10^{9} / 1$ white cells, mainly polymorphs, and numerous pleomorphic Gram-negative rods on microscopy. The peripheral blood showed a neutrophil leucocytosis of $17.8 \times 10^{9} / 1$. Both CSF and blood grew Haemophilus influenzae type b.

Immediate treatment was begun with chloramphenicol $150 \mathrm{mg}$ intravenously every 4 hours $(90 \mathrm{mg} / \mathrm{kg} / 24 \mathrm{~h})$. After 72 hours the level of consciousness, tachycardia, and fever had not improved and a further CSF specimen showed $2.0 \times 10^{9}$ white cells/l, with organisms still present on microscopy. This CSF specimen and a further blood culture also grew Haemophilus influenzae.

The original sensitivity plate was then reappraised and the zone of inhibition around the $25-\mu \mathrm{g}$ chloramphenicol disc was shown to be slightly smaller than that given by a control strain. A test for penicillinase production by the organism gave a negative result: Chloramphenicol was therefore stopped and treatment changed to ampicillin $10 \mathrm{mg}$ intrathecally once, and $400 \mathrm{mg}$ intravenously every 4 hours $(250 \mathrm{mg} / \mathrm{kg} / 24 \mathrm{~h})$.

Steady clinical improvement followed. The CSF was sterile after three days and pyrexia and tachycardia resolved after 10 days. Oral amoxycillin was substituted after seven days in doses up to $2 \mathrm{~g} / 24 \mathrm{~h}$ and stopped after 14 days, since when the child has remained well.

The minimum inhibitory concentration of chloramphenicol for this organism was $8 \mathrm{mg} / \mathrm{l}$ (control strain $0.5 \mathrm{mg} / \mathrm{l}$ ) and that of tetracycline $32 \mathrm{mg} / 1$ (control strain $1.0 \mathrm{mg} / \mathrm{l}$ ), using the agar plate incorporation method.

A strain of Haemophilus influenzae type b resistant to chloramphenicol and tetracycline was isolated from the throat of the 4-year-old brother, but non-typable strains from the mother, father, and babysitter were sensitive to both antibiotics.

The patient had been previously well, apart from otitis media four month earlier, which had been treated with penicillin. The rest of her family had also been well and had used neither chloramphenicol nor tetracycline in the previous five years.

\section{Comment}

The only other strain of chloramphenicol-resistant Haemophilus influenzae type b so far reported caused meningitis in a 9-month-old infant from Philadelphia; it was also tetracycline resistant. This resistance was probably plasmid-mediated, as in the non-typable strain isolated in Holland. ${ }^{2}$ This has grave implications for future treatment. Ampicillin has been considered to be a safe and effective antibiotic for treating infections caused by Haemophilus influenzae but increasing numbers of treatment failures have been reported these are explained by inadequate doses, relatively poor penetration of meninges, or bacterial resistance due to the production of $3-C$ lactamase. ${ }^{3}$ Intravenous chloramphenicol penetrates readily into the $\mathrm{CSF}$ and has previously been considered to be active against alf strains of Haemophilus influenzae. The possibility of resistance to either or both these antibiotics emphasises the importance of per-을 forming sensitivity tests whenever invasive strains are isolated and of reculturing CSF and blood when early clinical response is un- $\mathbb{\Phi}$ satisfactory. A less potent chloramphenicol disc-for example $\frac{2}{x \nu}$ $5 \mu \mathrm{g}$-might facilitate recognition of resistant strains. As advocated by the American Academy of Pediatrics, ${ }^{4}$ combination of chloram- $\overrightarrow{0}$ phenicol and ampicillin as initial treatment for Haemophilus influenzaemeningitis may be considered. Antibiotic antagonism is, however $\vec{\omega}$ a theoretical objection and combination therapy may actually increase the risk of long-term complications. ${ }^{5}$

We are grateful to Dr J D Baum for permission to report details of this case. $1976,25,386$

2 van Klingeren, B, van Embden, J D A, and Dessens-Kroon, M, Antimicrobial Agents and Chemotherapy, 1977, 11, 383.

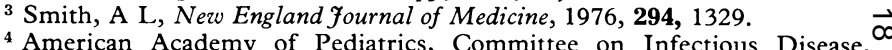
Pediatrics, 1976, 57, 417.

${ }^{5}$ Lindberg, J, et al, Pediatrics, 1977, 60, 1.

(Accepted 10 November 1977)

Departments of Paediatrics and Pathology, Churchill Hospital, Oxford

ANN-LOUISE KINMONTH, MB, senior house physician

C N STORRS, MRCP, DCH, paediatric senior registrar

R G MITCHELL, DM FRCP, consultant microbiologist

\section{Psittacosis masquerading as rheumatic fever}

It is now generally accepted that the diagnosis of rheumatic fever is based on the modified Jones's criteria, ${ }^{1}$ in which evidence of a preced- $\frac{0}{3}$ ing streptococcal infection is paramount. We record a case in which an initial clinical diagnosis of rheumatic fever was made but in which subsequent serological evidence indicated infection by Chlamydia N psittaci rather than streptococci.

\section{Case report}

A 39-year-old salesman was admitted with a two-week history of general malaise, sweating, and shivering associated with a sore throat and an unproductive cough. Three days before admission he had developed acute paine and swelling and redness of the wrist, metacarpophalangeal, and proximal interphalangeal joints. This developed into a flitting arthritis, which affected \& the elbow, knee, ankle, shoulder, and temporomandibular joints. Two days ? before admission he had developed a red, patchy rash proximally on all limbs, which subsequently spread on to the trunk. Four days before admission his GP had prescribed oxytetracycline and soluble aspirin. He had no relevant medical history apart from longstanding, recurrent low back pain.

On admission the abnormal findings were that he was clammy, febrile $\left(38.5^{\circ}\right)$, and peripherally cyanosed, with signs of acute arthritis affecting carpal and metacarpophalangeal joints. He had a rash with the typical $?$ appearance of erythema marginatum affecting his trunk and proximal aspects of limbs. His pulse was $108 / \mathrm{min}$ and regular; the respiratory rate was $20 / \mathrm{min}$; and there was a soft systolic ejection murmur over the aortic area. An electrocardiogram showed sinus tachycardia with right bundle-branch block. A chest $x$-ray film showed minor patchy shadowing at the right lung base. The results of routine biochemical tests were all normal, but he had a mild normochromic normocytic anaemia of $12.6 \mathrm{~g} / \mathrm{dl}$, with a WBC $13 \times 10^{9} / 1$ (neutrophilia) and ESR $116 \mathrm{~mm}$ in first hour (Westergren). Treatment with penicillin V $500 \mathrm{mg}$ six-hourly and soluble aspirin $600 \mathrm{mg}$ four-hourly with bed 